\title{
O kłopotach z rozpoznaniem rytmu serca w zapisie EKG, część 1
}

\section{About problems with ECG heart rhythm recognition, part 1}

\section{Rafał Baranowski, Małgorzata Łodyga}

Klinika Zaburzeń Rytmu Serca Instytutu Kardiologii w Warszawie

Spoczynkowy zapis elektrokardiograficzny (EKG) to "fotografia” aktywności elektrycznej serca. Można by dodać, że chwilowej aktywności, ponieważ zapis obejmuje zwykle kilka sekund. WXXI wieku spoczynkowe badanie EKG ma przede wszystkim umożliwić rozpoznanie rytmu serca, ocenę przewodzenia w sercu, czas trwania okresu repolaryzacji oraz identyfikację pochodzenia zaburzeń rytmu serca. W zakresie tych parametrów obecnie praktycznie nie ma alternatywy w stosunku do EKG. Pozostałe elementy oceny, takie jak ocena przerostów, martwicy czy niedokrwienia, można przeprowadzić również innymi metodami. W odniesieniu do tych parametrów EKG stanowi metodę uzupełniającą.

Fundamentem opisu EKG jest ocena rytmu wiodącego. W niniejszym opracowaniu zajmiemy się problemami, jakie mogą wyniknąć w tym pierwszym momencie oceny EKG.

Przede wszystkim należy przypomnieć o znaczeniu jakości wykonania EKG. To, że artefakty zapisu mogą utrudnić ocenę EKG, zostało już opisane wcześniej w artykule „Spokojnie, to tylko artefakty!” w numerze 2 czasopisma Choroby Serca i Naczyń z 2018 roku. Nie trzeba sięjednak posługiwać tak skrajnymi przykładami. Popatrzmy na zapis EKG z niewielką

Adres do korespondencji:

prof. dr hab. n. med. Rafał Baranowsk

Klinika Zaburzeń Rytmu Serca

Instytut Kardiologii w Warszawie

ul. Alpejska 42, 04-628 Warszawa

tel. 228154014 , faks 223434502

e-mail: rbaranowski@ikard.pl „domieszką" artefaktów, w którym niski woltaż załamków P sprawiał problem w ocenie rytmu (ryc. 1).

Do wyniku badania jest dołączony opis automatyczny w brzmieniu "rytm nieokreślony”, co najlepiej odzwierciedla problem oceny rytmu. Zapis jest dość dobrej jakości, niestety niska amplituda załamków $\mathrm{P}$ „wtapia się" w niskoamplitudowe artefakty linii izoelektrycznej. Jeśli dokładniej przyjrzymy się temu zapisowi, to dostrzeżemy załamki P w czterech ewolucjach w odprowadzeniu II i w pięciu w odprowadzeniu V2. Prawdopodobnie, jak już wspomniano, pacjent ma rytm zatokowy, na pewno jednak nie można rozpoznawać migotania przedsionków. Co zrobić w przypadku dalszych wątpliwości? Oczywiście należy powtórzyć badanie EKG, zwracając jeszcze większą uwagę na jakość wykonania. Czy warto zwiększać amplitudę? Zwykle to nie jest dobry pomysł, ponieważ wtedy wzmocnieniu ulega również amplituda artefaktów, co utrudnia analizę. Na pewno warto wykonać zapis na tak zwanej dłuższej taśmie, a następnie wybrać do oceny odcinki mniej zniekształcone artefaktami.

Jeżeli nie znajdziemy załamków P, to nie dokonujmy „z automatu" rozpoznania migotania przedsionków. Sam brak załamków P nie oznacza bowiem, że występuje migotanie. Przypatrzmy się teraz kolejnemu zapisowi (ryc. 2).

Patrząc na zapis z ryciny 2 , wyobraźmy sobie, że oceniamy rytm na podstawie dwunastu odprowadzeń. Trudno znaleźć załamki P. Jeden "podejrzany" fragment zapisu to druga ewolucja — wsteczne P? Widoczne za zespołem QRS (najlepiej w odprowadzeniach II, III i aVF). Spójrzmy teraz na dolny pasek — odprowadzenie II; oprócz pierwszych czterech ewolucji widocznych w układzie dwunastoodprowadzeniowym widzimy kolejnych sześć, 


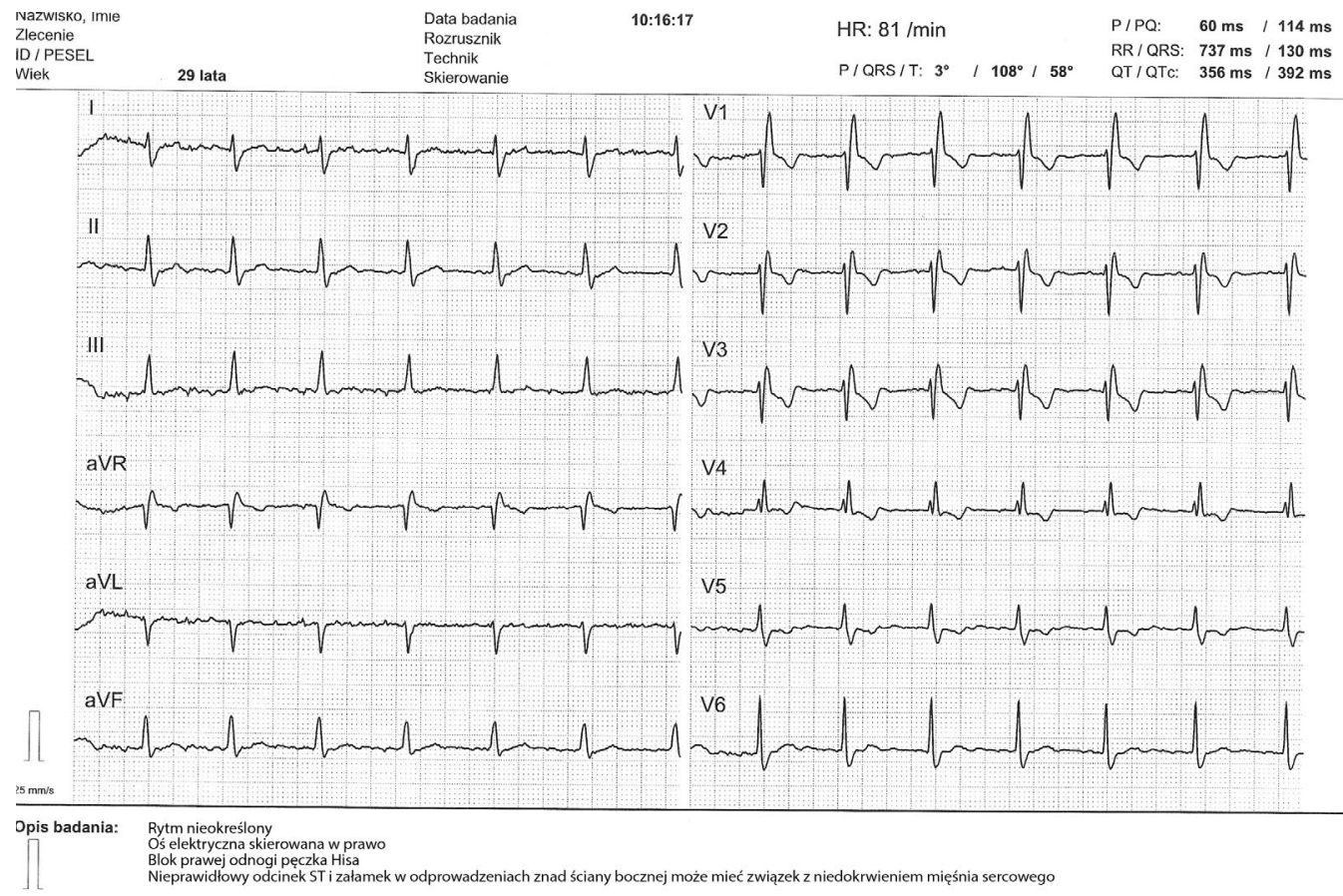

Rycina 1. Zapis elektrokardiograficzny, w którym interpretacja rytmu serca jest utrudniona przez niewielkie artefakty i niską amplitudę załamka P. W odprowadzeniach II i V2 widoczne załamki P. Ten chory ma najprawdopodobniej rytm zatokowy, dodatkowo widać odchylenie osi w prawo i blok prawej odnogi pęczka Hisa

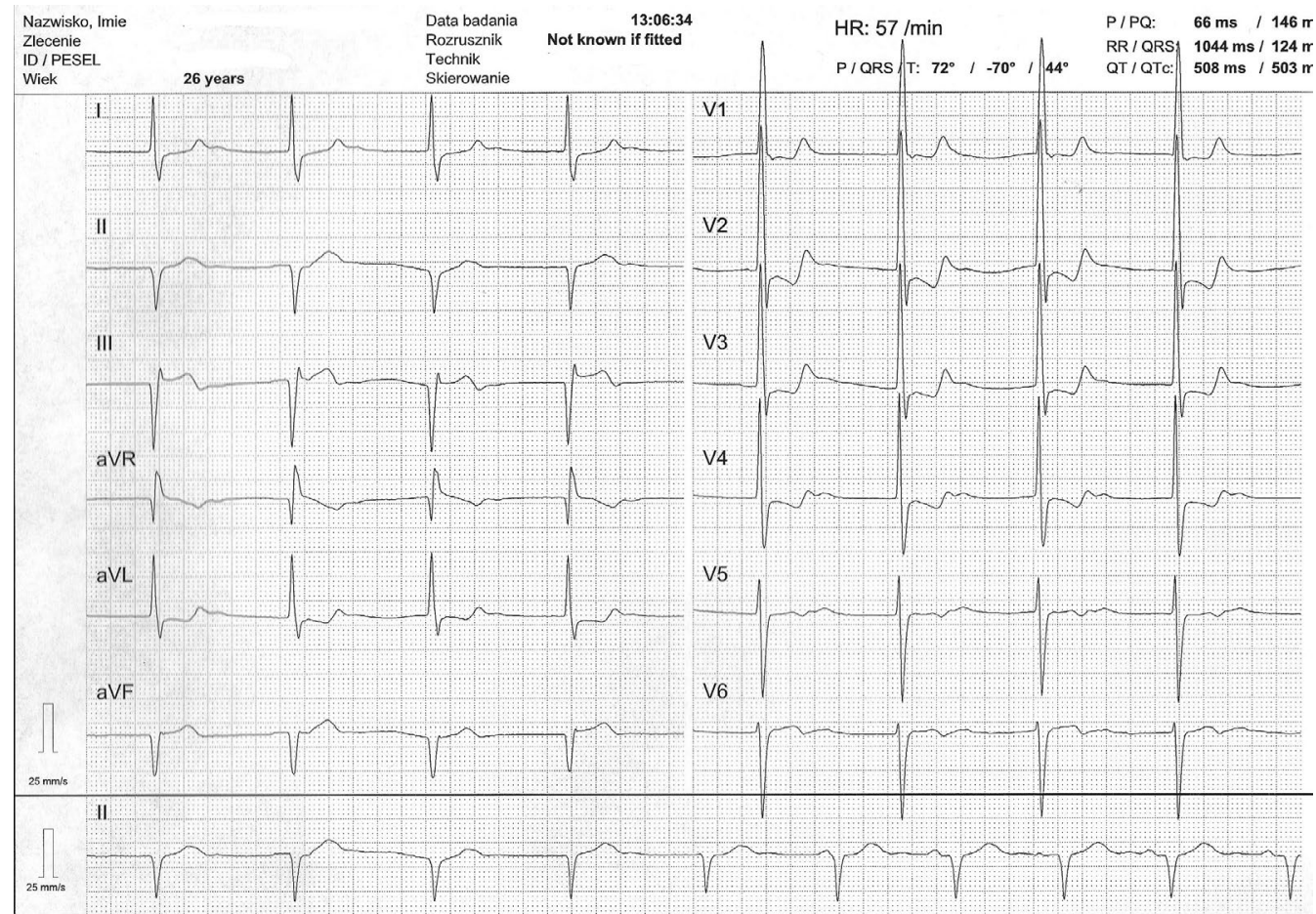

Rycina 2. Zapis elektrokardiograficzny wykonany u pacjenta z rytmem z łącza przedsionkowo-komorowego oraz z widocznym później (dolny pasek) rytmem prawdopodobnie zatokowym. Zapis synchroniczny - obserwujemy te same ewolucje w odprowadzeniach kończynowych i przedsercowych. Ponadto widoczne: odchylenie osi w lewo, nietypowy obraz bloku prawej odnogi pęczka Hisa lub po prostu zespoły QRS zniekształcone przerostem prawej komory, załamki Q w odpowadzeniach II, III i aVF. Jest to zapis u pacjenta ze skorygowanym przełożeniem wielkich pni naczyniowych 

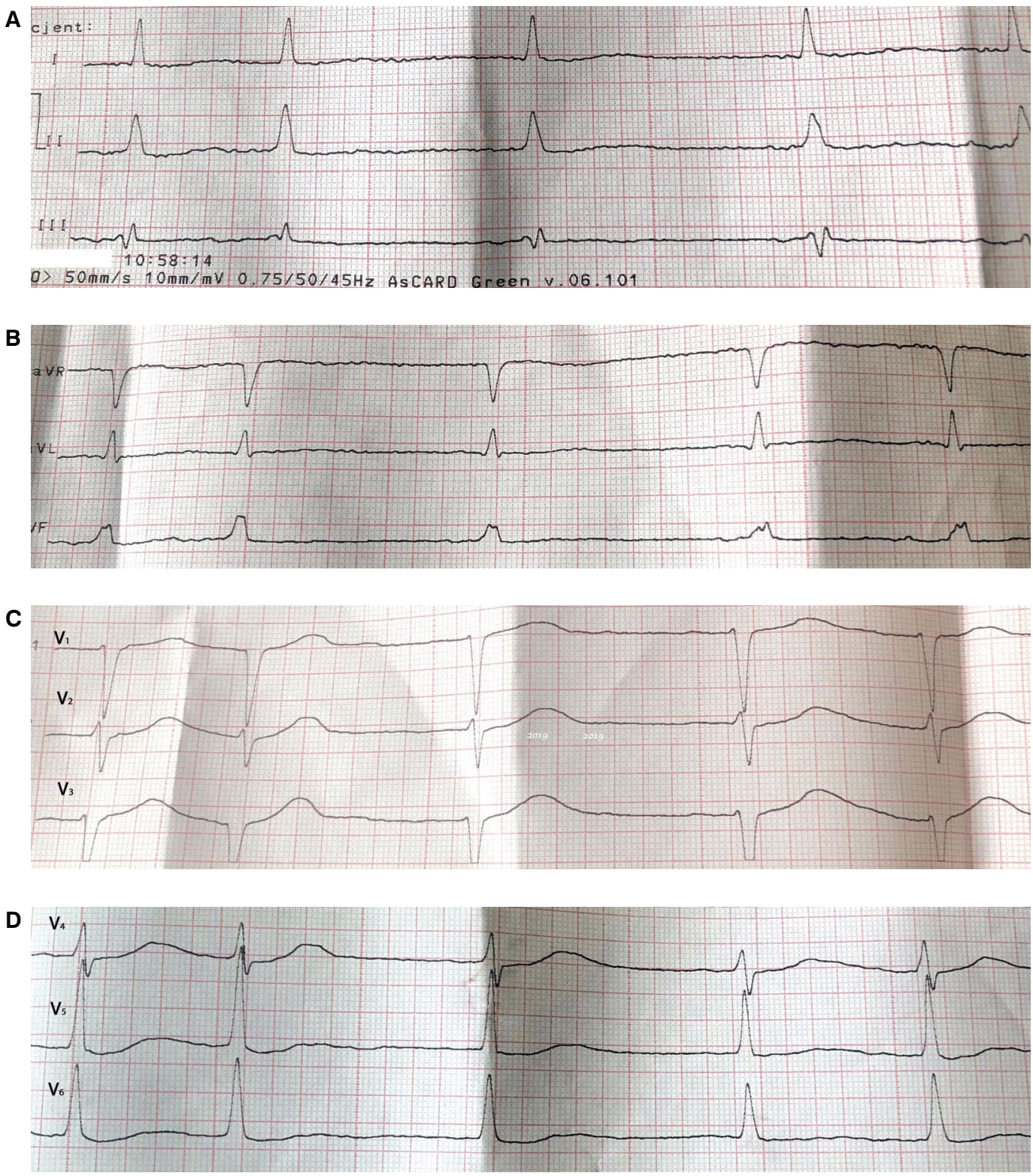

Rycina 3A-D. Badanie elektrokardiograficzne wykonane z przesuwem $50 \mathrm{~mm} / \mathrm{s}$. Zapis synchroniczny. Trudne do rozpoznania załamki $\mathrm{P}$, najlepiej widoczne w odprowadzeniach aVF i III. Czyżby przedwczesne pobudzenia przedsionkowe?

a wśród nich ewidentne załamki P. Dłuższy zapis EKG daje nam jasną odpowiedź — pacjent ma rytm z łącza przedsionkowo-komorowego, okresowo rytm zatokowy. Na pewno nie występuje tu migotanie przedsionków.

Teraz popatrzmy, jak możemy sobie sami utrudnić ocenę rytmu. Utrudnić, wykonując zapis z przesuwem $50 \mathrm{~mm} / \mathrm{s}$. W związku z takim sposobem wykonania EKG "małe i obłe" załamki - a takie bywają załamki P — stają się jeszcze mniej widoczne. Popatrzy na przykład nadesłany przez Panią dr Małgorzatę Łodygę (ryc. 3A-D).

$\mathrm{Na}$ tym zapisem trwała dyskusja na Facebooku w grupie „Lubię EKG”. Zastanawiano się, czy pacjent ma rytm zatokowy czy też migotanie przedsionków. To bardzo istotna klinicznie różnica, inne jest bowiem — jak wiadomo - postępowanie, inne jest leczenie. Można się dopatrzyć załamków P, zwłaszcza w odprowadzeniach III i aVF, ale wątpliwości pozostają. U tego samego pacjenta wykonano zapis z przesuwem $25 \mathrm{~mm} / \mathrm{s}$ (ryc. 4).

Analizując zapis wykonany z przesuwem na $25 \mathrm{~mm} / \mathrm{s}$, nie mamy wątpliwości - załamki $\mathrm{P}$ są ewidentnie widoczne w odprowadzeniach II, III i aVF. Nie ma migotania przedsionków, jest natomiast arytmia przedsionkowa. Ten przykład ilustruje, jak przesuw $50 \mathrm{~mm} / \mathrm{s}$ może się stać „zaproszeniem” do kłopotów 
A

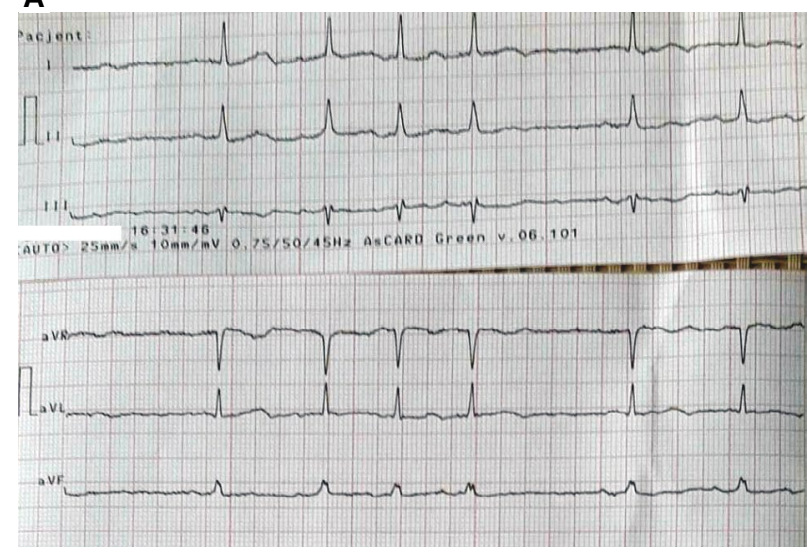

B

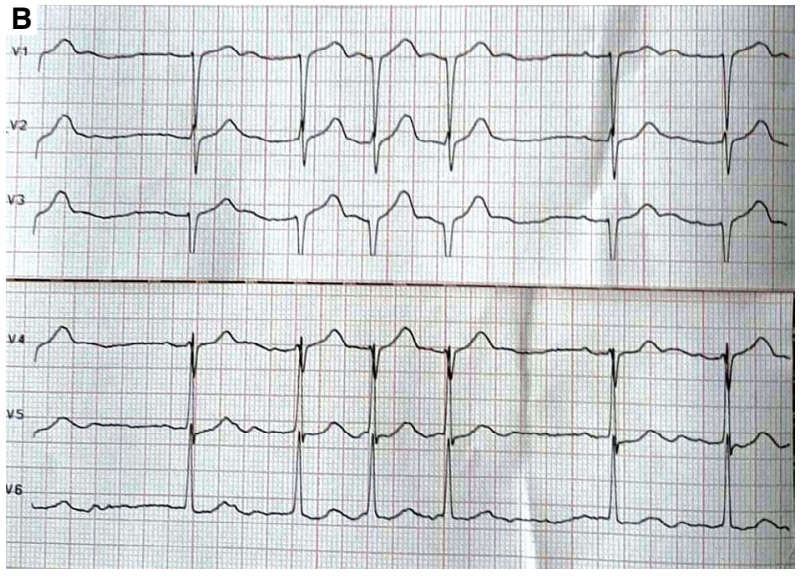

Rycina 4A, B. Zapis elektrokardiograficzny wykonany u tego samego pacjenta, co zapis ukazany na rycinie 3 , tym razem z przesuwem $25 \mathrm{~mm} / \mathrm{s}$. Załamki P bardzo dobrze widoczne w odprowadzeniach II, III i aVF. Teraz można bez wątpliwości rozpoznać pobudzenia zatokowe oraz arytmie przedsionkowe

w interpretacji zapisu EKG. Na pewno nie sprzyja identyfikacji załamków P.
Temat trudności w ocenie rytmu serca będziemy kontynuowali w następnym numerze. 